\title{
UNINDO TEORIA A PRÁTICA NA APLICAÇÃO DO TEMA: MICROBIOLOGIA NO ENSINO DE CIÊNCIAS
}

\author{
Patrícia Batista de Oliveira ${ }^{1}$ \\ Alexandra A. Zorzal ${ }^{2}$ \\ Monique Vargas de Gouvêa ${ }^{3}$ \\ Simone Fernandes ${ }^{4}$ \\ Andreia da Silva ${ }^{5}$
}

Resumo: O projeto PIBID/CAPES proporciona aos bolsistas integrantes do subprojeto em Ciências/Interdisciplinar a experiência de interagir com alunos do Ensino fundamental, preparando o licenciando para o cotidiano escolar e, assim, buscando novas estratégias para o ensino/aprendizagem de Ciências. O trabalho foi desenvolvido com uma turma do $6^{\circ}$ ano do ensino fundamental e teve como objetivo apresentar uma atividade prática de microbiologia no ensino de ciências, a fim de despertar o interesse dos alunos, unindo teoria à prática. Buscou-se desenvolver uma metodologia que o conteúdo não fique somente no teórico, que tenha uma prática para promover habilidades e assim relacionar o conhecimento prévio de cada estudante com algumas situações do cotidiano. Diante desse método de unir à teoria a prática os alunos mostraram-se mais interessados e participativos, percebendo-se uma mudança significativa no entendimento dos conteúdos. Desta forma, fica evidente que as aulas práticas no Ensino de Ciências são estimulantes e fundamentais para que os alunos construam seu conhecimento.

Palavras-chave: Atividade experimental; Ensino Fundamental; Bactérias.

\footnotetext{
1 Ciências Biológicas Licenciatura/Universidade Federal do Espírito Santo, Brasil. E-mail: patricia.bio77@gmail.com.

2 Ciências Biológicas Licenciatura/Universidade Federal do Espírito Santo, Brasil. E-mail: alexandra.zorzal@gmail.com.

3 Ciências Biológicas Licenciatura/Universidade Federal do Espírito Santo, Brasil. E-mail: monique.gouvea@hotmail.com.

${ }^{4}$ Física/Universidade Federal do Espírito Santo, Brasil. E-mail: simonenfis@gmail.com.

${ }^{5}$ Física/Universidade Federal do Espírito Santo, Brasil. E-mail: andreiafisica@gmail.com.
} 